\title{
Uso de Membranas Bacterianas como Fuente para la Elaboración de Liposomas como Adyuvantes
}

\author{
Loreto Zepeda Crestto ${ }^{1}$, Sonia Vidal Vilches ${ }^{1}$, Leonardo Sáenz Iturriaga ${ }^{1}$ \\ ${ }^{1}$ Centro biotecnológico BioVeTec, Departamento de Ciencias Biológicas Animales, Facultad de \\ Ciencias Veterinarias y Pecuarias, Universidad de Chile, Santiago, Chile. Email: \\ leosaenz@,uchile.cl
}

\begin{abstract}
RESUMEN
La formulación de liposomas como adyuvantes a partir de membranas interna (MI) y externa (ME) de bacterias Gram(-) permite estimular al sistema inmune ya que incorporan patrones moleculares asociados a microorganismos (MAMPs) en su estructura, facilitando el reconocimiento de células presentadoras de antígeno como células dendríticas y macrófagos. Para la obtención de los liposomas, se utilizó la cepa de Escherichia coli (JM109) y posterior a un proceso de solubilización con detergentes se pudo extraer diferencialmente ambas membranas. La formación de los liposomas se produjo por la diálisis continua a la que se sometió la muestra. Los liposomas fueron evaluados en cuanto a tamaño, características físicoquímicas y eficiencia de incorporación de un antígeno en su estructura. Los liposomas generados de MI y ME incluyen MAMPs, miden $200 \mathrm{~nm}$ aproximados, presentan carga negativa e incorporan una proteína antigénica con un porcentaje de eficiencia variable siendo mayor en los producidos a partir de la MI.
\end{abstract}

Palabras claves: liposomas, membranas interna y externa, MAMPs, adyuvantes.

\section{Introducción}

La principal herramienta que permite detener la invasión de microorganismos patógenos en las distintas especies de origen animal es la vacunación. Los protocolos de vacunación tienen por objeto la presentación de antígenos exógenos a células presentadoras de antígeno (CPA) asociado a un adyuvante que potencie la presentación antigénica y que genere la consecuente activación de linfocitos $\mathrm{T}$ y B (Heit et al., 2008). La producción de anticuerpos neutralizantes (inmunidad humoral) y la activación de importantes poblaciones de células $\mathrm{T}$ (inmunidad celular) son la clave del éxito terapéutico, para lo cual es necesaria la completa activación de las CPA (Mescher et al., 2006).

Las células de la inmunidad innata que controlan el proceso de presentación antigénica son las células dendríticas (CD) y tienen un rol crucial en la activación de células $T$, pudiendo controlar parte importante de la inmunidad adaptativa en respuesta a la internalización y procesamiento de antígenos a través de la vía de moléculas de histocompatibilidad clases I y II (MHC I y MHC II) y la presentación de péptidos antigénicos a los linfocitos T CD4+ y CD8+ (Reddy et al., 2006).

Las señales coestimuladoras necesarias para la diferenciación de la respuesta inmune adaptativa se activan cuando las $\mathrm{CD}$ interactúan con patrones moleculares asociados a microorganismos (MAMPs, del inglés Microorganism Associated Molecular Pattern) es decir, estructuras altamente conservadas que están presentes en la mayoría de los microorganismos, incluidos los patógenos. Los MAMPs tienen múltiples efectos en las señales generadas por las células del sistema inmune innato $\mathrm{y}$, por lo tanto, pueden ser útiles como adyuvantes 
naturales en el impulso de la respuesta adaptativa (Kaufmann, 2004). Algunos MAMPs son el lipopolisacárido (LPS), lipoproteínas de membrana, proteínas de membrana externa, DNA desmetilado con secuencias $\mathrm{CpG}$, entre otros. La identificación de los MAMPs se realiza a través de la asociación ligando-receptor entre los MAMPs (también llamados "señales de peligro") y una serie de receptores denominados Toll Like Receptors (TLR) y otros como Pattern Recognition Receptors (PRR) que se encuentran en varias células del sistema inmune innato y que incluyen a las CPA (macrófagos, CD y células B), responsables de la activación linfocitaria.

Vacunas y Adyuvantes

Las necesidades actuales, en relación a las enfermedades emergentes, determinan que las tradicionales vacunas existentes, basadas en patógenos vivos atenuados, organismos inactivados o toxinas bacterianas inactivadas, sean modificadas para generar una respuesta inmune más efectiva, segura y duradera. Con el fin de mejorar esta respuesta se han utilizado adyuvantes para generar una respuesta inmune cuando se administran conjuntamente con un antígeno de elección (Heit et al., 2008). Los adyuvantes facilitan el reconocimiento del antígeno por parte de las CPA. La capacidad de activar e inducir en las CPA, es una característica de los adyuvantes destinados a estimular los receptores presentes en estas células como los PRR, ya que éstos reconocen principalmente moléculas de origen bacteriano (Wagner y Bauer, 2006; Heit et al., 2008).

Las vacunas peptídicas o de subunidad, son una versión purificada de un patógeno o un fragmento peptídico de éste, que funciona como un antígeno vaccinal. Las proteínas y péptidos antigénicos usados como subunidades en vacunas, frecuentemente son de baja inmunogenicidad cuando son administradas solos, por ello son formulados con la adición de adyuvantes, vehículos de transporte o ambas cosas para mejorar la inmunogenicidad (Richards et al., 1996). La baja inmunogenicidad que presentan se debe a que carecen de la mayoría de los MAMPs como LPS, lipoproteínas de membrana, DNA desmetilado, entre otros (Sáenz et al., 2009).

Existen diferentes tipos de adyuvantes para ser usados en vacunas. Se pueden mencionar los que funcionan como sistemas de liberación de partículas y que incluyen micropartículas, emulsiones, ISCOMs, virosomas, liposomas, entre otros. Éstos tienen dimensiones que los hacen comparables a los patógenos, lo que permite al sistema inmune reconocerlos de manera más eficiente. Los liposomas han mostrado ser efectivos como vehículos de vacunas $y$ tienen buena actividad adyuvante (Richards et al., 1996).

Los liposomas pueden ser sintéticos o naturales. Éstos se definen como vesículas compuestas de una bicapa de fosfolípidos y colesterol con un compartimento interno acuoso. Los fosfolípidos forman parte de la estructura primaria y el colesterol le confiere características de rigidez a la membrana generando así una mayor estabilidad (Richards et al., 1996; Peetla et al., 2009). Estas estructuras fosfolipídicas son similares a las membranas celulares y de gran aplicación farmacéutica. Además se describe que serían capaces de inducir una potente respuesta inmune humoral, sin la generación de granulomas en el sitio de inyección ni reacciones de hipersensibilidad (Piovesan y Andrade, 2004).

Los liposomas son muy versátiles en sus características físicoquímicas, inmunológicas, de composición y tienen un tamaño entre $50 \mathrm{~nm}$ y 10 $\mu \mathrm{m}$. Debido a sus características son usados como transportadores de drogas biocompatibles, péptidos, proteínas, DNA plasmidial, oligonucleótidos o ribosomas, para la industria farmaceútica, cosmética y propósitos bioquímicos (Ulrich, 2002; Kaufmann, 2004).

Una característica fisicoquímica importante es el potencial zeta del liposoma, el cual indica la interacción que se produce en partículas en suspensión, permitiendo medir la velocidad de las mismas mediante movimientos de atracción o repulsión, dependiendo de la carga que posean y el ambiente en el que se encuentran (Kaufmann, 2004).

El uso de membranas provenientes de diferentes microorganismos sería una eficiente vía al ser usadas como adyuvantes, ya que tendrían incorporados en su estructura los MAMPs que facilitarían el reconocimiento por parte del sistema inmune (Robinson et al., 2003).

Las bacterias Gram (-) presentan una envoltura celular compuesta por una membrana citoplasmática (membrana interna), una pared celular delgada de péptidoglicano, que rodea a la anterior, y una membrana externa que recubre la pared celular de estas bacterias.

Ambas membranas, interna (MI) y externa (ME), presentan diferencias estructurales, distintas 
concentraciones, tipos de MAMPs asociados, y métodos de solubilización para su obtención. Estas características podrían determinar diferencias en la presentación antigénica. Los liposomas que incluyen ME y MI de origen bacteriano y que incorporan proteínas de membrana se conocen como proteoliposomas (Kaufmann, 2004; Pérez et al., 2007). Estas vesículas son obtenidas mediante procesos como la solubilización en solventes orgánicos o detergentes que son retirados posteriormente en un proceso de diálisis. Durante el proceso de solubilización de membranas y reconstitución de vesículas por medio de la extracción del solvente, quedan atrapados componentes del microorganismo, como DNA, proteínas de membrana o LPS, estructuras esenciales para el reconocimiento por parte de las CD y macrófagos para ser presentados posteriormente a los linfocitos (Pérez et al., 2004).

El objetivo de este estudio es formular y caracterizar liposomas a partir de membranas internas y externas de bacterias Gram(-) y determinar su capacidad para incorporar un antígeno peptídico como posible modelo de formulación de vacunas

\section{Materiales y métodos}

Extracción de lípidos de membrana externa e interna para formular liposomas

Solubilización de MI y ME de Escherichia coli (cepa JM 109)

La bacteria Gram (-) E.coli $\quad$ JM 109 (recA1, endA1, gyrA96, thi-1, hsdR17 (rK-mk+), e14-(mcrA-), supE44, relA1, $\quad \Delta$ (lac-proAB)/F' [traD36, proAB + , lac Iq, lacZ $\Delta M 15]$ ), cepa no patógena, fue la fuente de membranas para la reconstitución de liposomas.

Un cultivo bacteriano de $1000 \mathrm{ml}$ de E.coli con $24 \mathrm{~h}$ de incubación a $37^{\circ} \mathrm{C}$ fue sometido a centrifugación por $10 \mathrm{~min}$ a $7000 \mathrm{x} \mathrm{g}$. El sedimento se lavó y resuspendió en $40 \mathrm{ml}$ de tampón Tris- $\mathrm{HCl}$ (10 mM; $\mathrm{pH} 8,0)$. Las bacterias se lisaron por sonicado en hielo (pulsos de $100 \mathrm{~s}, 40 \%$ de amplitud en Digital Sonifier $450 \AA)$. La mezcla fue centrifugada a $7000 \mathrm{x}$ $\mathrm{g}$ por $5 \mathrm{~min}$ en microcentrífuga y el sobrenadante se recuperó y se centrifugó a 14000 x g por $30 \mathrm{~min}$. A partir de este sedimento que contiene la fracción de membranas, se resuspendió en $20 \mathrm{ml}$ de tampón
(Tris-HCl 10 mM; pH 8, MgCl2 10 mM, Tritón X$1002 \%$ ), luego se agitó vigorosamente en vórtex e incubó por $30 \mathrm{~min}$ a $37^{\circ} \mathrm{C}$. La ME al ser insoluble en detergentes no iónicos como el tritón X-100, se sedimentó mediante centrifugación a $14000 \mathrm{x}$ g por $30 \mathrm{~min}$. Se separó el sobrenadante con la MI y el sedimento con la $\mathrm{ME}$ se resuspendió en $16 \mathrm{ml}$ de tampón Tris-HCl 10mM; pH 8, MgCl2 10 mM, SDS 2\% (Bucarey, 2006).

Formulación de liposomas en conjunto con una proteína antigénica

\subsection{Incorporación del antígeno}

Ambas membranas solubilizadas, MI y ME, fueron tratadas con una solución de proteína para obtener una concentración de $0,5 \mathrm{mg}$ por cada $\mathrm{ml}$ de solución de membranas. Las proteínas usadas fueron, BSA (albúmina sérica bovina) y OVA (ovoalbúmina).

\subsection{Reconstitución de liposomas}

Al remover progresivamente el detergente desde las membranas solubilizadas, se produce la formación de vesículas de bicapas lipídicas con la solución de proteína incorporada. El detergente se removió mediante diálisis continua, utilizando membranas de 15000 de tamaño de corte (SPECTRA/POR $®$ ) y mantenidos en cuatro litros de agua desionizada con constante agitación para favorecer la difusión del detergente. El agua desionizada fue cambiada dos veces al día durante cinco días consecutivos.

\subsection{Secado por atomización de los liposomas}

El secado por atomización ("Spray Dryer") es un sistema de secado que reduce tiempos de uso y material, para convertir incluso, pequeñas cantidades de sustancia en polvo. Permite mayor rendimiento y tiempos de procesamientos más cortos frente a la liofilización. Los bajos tiempos de residencia y el efecto de refrigeración a través de la evaporación posibilitan trabajar eficazmente con productos sensibles a la temperatura.

Este proceso incluye cuatro etapas: atomización del producto en una boquilla, contacto con aerosoles, secado de las gotas de rocío y colección del producto sólido (Chougule et al., 2007). El equipo que se usó fue Buchi B-290 y pulverizó la mezcla que contenía los liposomas mediante atomización de aire comprimido caliente a través de una boquilla de 0,7 mm. Los parámetros usados fueron los siguientes: 
temperatura de entrada de $150{ }^{\circ} \mathrm{C}$, temperatura de salida de $90 \pm 5^{\circ} \mathrm{C}, 100 \%$ de aspiración y un flujo de aire de $30 \mathrm{~mm}$. El polvo obtenido con los liposomas, fue mantenido a $4{ }^{\circ} \mathrm{C}$ antes de usar.

\section{Caracterización de liposomas}

\subsection{Identificación de MAMPs}

La presencia de LPS, proteínas de membrana (porinas) y DNA contenidos en los liposomas, fueron determinados con el ensayo Purpald, SDS-PAGE y electroforesis en geles de agarosa respectivamente (Pérez et al., 2007).

\subsection{Ensayo purpald}

Los extremos residuales azucarados del LPS como el kdo (2-ceto-3-deoxioctonato) y la heptosa son sometidos a una oxidación peryódica a temperatura ambiente $y$ el rendimiento cuantitativo del formaldehido es medido por el reactivo purpald (Lee y Tsai, 1999).

En una placa de 96 pocillos, se agregó $50 \mu \mathrm{l}$ de la muestra que contiene el LPS junto a su duplicado. Se adicionó $50 \mu \mathrm{l}$ de ácido peryódico (NaIO4) $32 \mathrm{mM}$ y se incubó por $25 \mathrm{~min}$, luego se agregó $50 \mu \mathrm{l}$ de reactivo purpald $136 \mathrm{mM}$ en hidróxido de sodio $(\mathrm{NaOH}) 2 \mathrm{~N}$, se incubó por $20 \mathrm{~min}$ y se adicionó $50 \mu \mathrm{l}$ NaIO4 $64 \mathrm{mM}$ e incubó por otros $20 \mathrm{~min}$. La espuma se eliminó con $20 \mu \mathrm{l}$ de 2 - propanol. La absorbancia de cada pocillo se midió a $550 \mathrm{~nm}$. Para la cuantificación de los niveles de LPS en cada muestra se generó una curva estándar con concentraciones conocidas de LPS (Sigma-aldrich).

2.6. Electroforesis en geles denaturantes de poliacrilamida (SDS-PAGE)

Se agregaron $10 \mu \mathrm{l}$ del tampón de carga (Tris $\mathrm{HCl}$ $200 \mathrm{mM}$, pH 6,8; DTT (ditiotreitol) $10 \mathrm{mM}$; Glicerol $20 \%$, SDS $10 \%$, Azul de bromofenol $0,05 \%$ ) a $10 \mu \mathrm{l}$ de la muestra que contiene los liposomas y se calentó la mezcla en un baño de agua hirviendo por $5 \mathrm{~min}$. Las concentraciones de acrilamida usadas fueron de $4 \%$ en el gel concentrador y $12,5 \%$ en el gel resolutivo $\mathrm{La}$ electroforesis se realizó a 150 volts constante usando estándares de proteína preteñidos como referencia. Una vez terminada la electroforesis, el gel fue sumergido en una solución de tinción con azul de Coomassie P250 por 2 h como mínimo, y se destiñó con una solución de ácido acético al 10\% (Bucarey, 2006).

\subsection{Electroforesis en geles de agarosa}

Los geles fueron preparados usando agarosa a una concentración de $1 \%$ en tampón TAE (Tris-acetato $40 \mathrm{mM}$; pH 8,0 y EDTA $1 \mathrm{mM}$ ) mezclados con gel red. Los geles se cargaron con $15 \mu \mathrm{l}$ de muestras por carril. La electroforesis se realizó a 90 volts constante por $40 \mathrm{~min}$. Las bandas de DNA presentes en los geles se visualizaron $y$ fotografiaron sobre un transiluminador ultravioleta.

\subsection{Determinación de la eficiencia de carga}

Para determinar la eficiencia de incorporación de la proteína antigénica en los liposomas se cuantificó la presencia de la proteína que permaneció soluble en el sobrenadante, utilizando la técnica de Bradford y BCA.

Para ello se centrifugó $400 \mu$ de cada muestra a $14000 \mathrm{x}$ g durante $30 \mathrm{~min}$ para sedimentar los liposomas. Del sobrenadante se sacaron $10 \mu \mathrm{l}$ y se mezcló con $500 \mu \mathrm{l}$ de reactivo de Bradford (Thermo Scientific () ) para ser finalmente medidos por espectrofotometría. El ensayo se repitió utilizando la técnica de BCA, el cual se basó en la preparación de $1 \mathrm{ml}$ de la solución de BCA (Thermo Scientific $\AA$ ) y $20 \mu \mathrm{l}$ de sulfato cúprico al $4 \%$, ambos se mezclaron con $50 \mu \mathrm{l}$ de la muestra, se incubaron por $30 \mathrm{~min}$ a $37^{\circ} \mathrm{C}$ y se midieron en espectofotómetro a $595 \mathrm{~nm}$.

\subsection{Caracterización de los liposomas}

La caracterización de los liposomas se realizó mediante la determinación de la forma, tamaño y potencial zeta de las muestras.

La morfología fue determinada por medio de microscopía electrónica de transmisión (TEM). Para realizar estos ensayos los liposomas fueron montados en grillas, teñidos con acetato de uranilo al $2 \%$ como tinción negativa $\mathrm{y}$ visualizados en microscopio TEM (Zeiss Electron Microscope EM 109). El tamaño y características fisicoquímicas como potencial zeta de los liposomas fueron medidos por medio del equipo ZetaPlus (Brokehaven Instruments). Para esto $10 \mu \mathrm{l}$ de cada muestra fueron resuspendidas en $20 \mathrm{ml}$ de una solución de $\mathrm{KCl}$ $1 \mathrm{mM}, \mathrm{pH} 5.5$

\section{Resultados y discusión}

Según lo obtenido de la solubilización de membranas, ambas, presentan diferentes 
concentraciones de porinas, DNA, LPS y permiten una desigual incorporación de las proteínas antigénicas, lo que determina finalmente diferencias en las características físicoquímicas de los liposomas generados y que son visualizados en el TEM.

En la Fig. 1 se puede observar una gran cantidad de proteínas de pesos moleculares similares a porinas que se encuentran preferentemente en los liposomas formulados a partir de ME. Esto es debido a que las bacterias Gram (-) tienen una MI rodeada de una ME que presenta en su estructura diversas proteínas, entre las cuales se destacan diferentes clases de porinas de membrana o canales proteicos que permiten el transporte pasivo de muchos iones, azúcares y aminoácidos a través de la ME (Sutcliffe y Harrington, 2004). Algunas porinas más representativas se encuentran entre los 30 y $46 \mathrm{KDa}$ (indicadas con flechas).

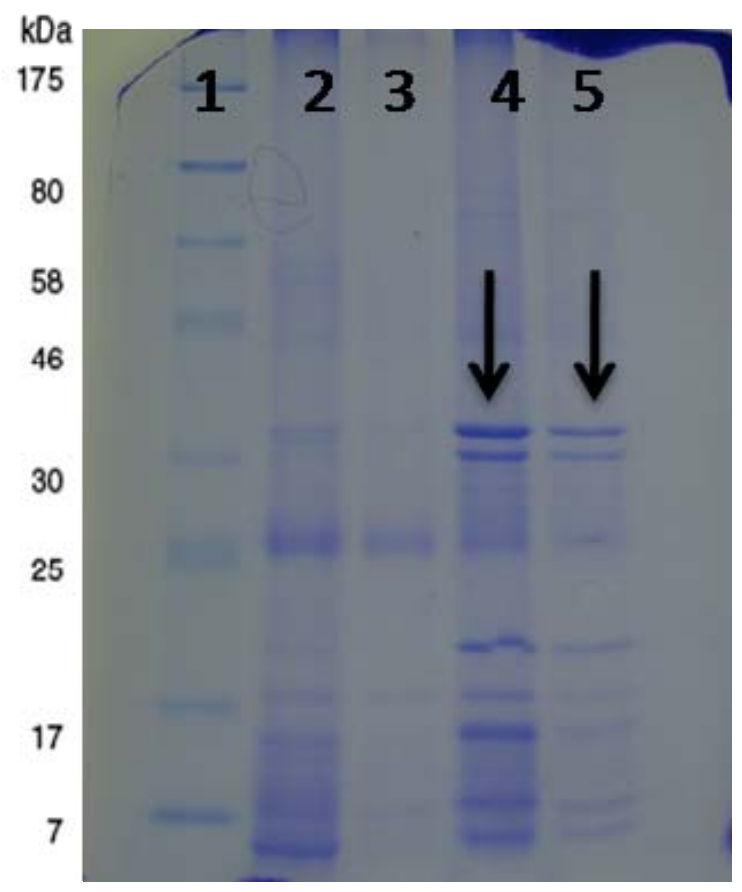

Fig. 1. Gel poliacrilamida SDS-PAGE 12,5\%. El carril 1 corresponde al estándar de peso molecular preteñido con tamaños entre los $7 \mathrm{KDa}$ y los 175 KDa. Los carriles 2 y 3 corresponden a la MI y los carriles 4 y 5 a la ME de la cepa JM 109 de E.coli.

En la Fig.2 se visualizan fragmentos correspondientes al DNA que se encuentra libre y unido a membrana, debido a que no presentan núcleo definido (Sutcliffe y Harrington, 2004). Considerando estas características, su unión a la ME se asociaría al proceso de solubilización realizado para separar ambas membranas. En la ME se observa claramente una banda (indicado con la flecha) de un tamaño aproximado de 10000 bp (pares de bases). En la MI también puede observarse, pero en menor cantidad.

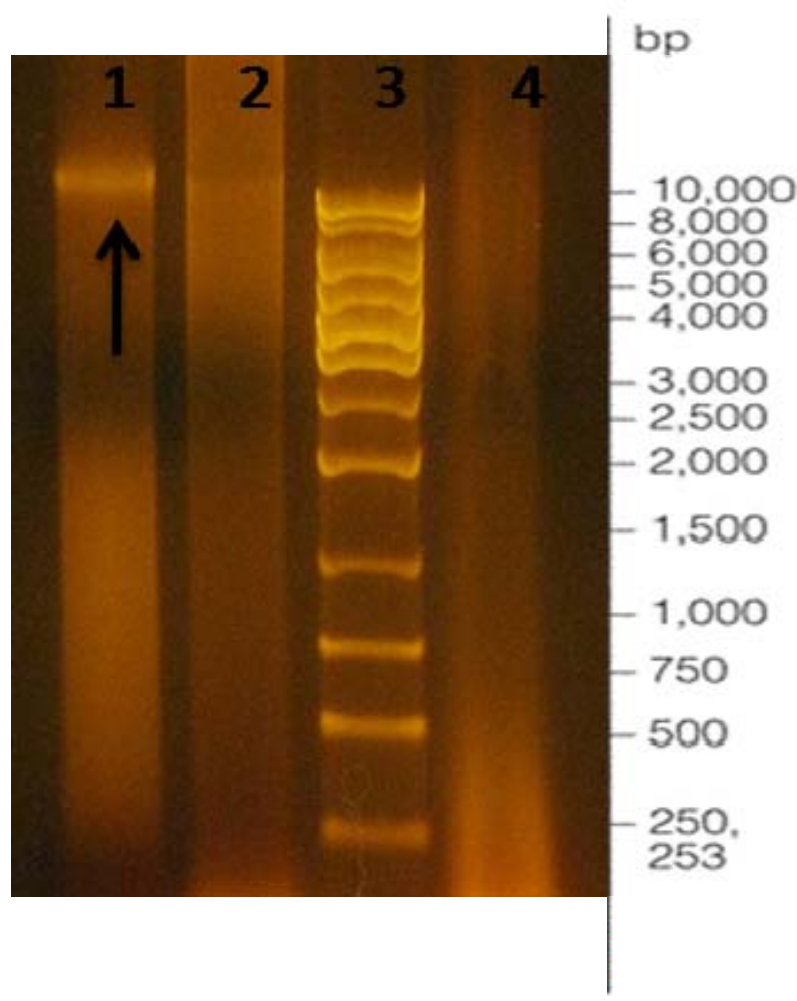

Fig. 2. Gel agarosa TAE 1\%. DNA bacteriano de una cepa JM 109 de E.coli en liposomas de MI y ME con proteínas incorporadas. El carril 1 corresponde a MEBSA (albúmina sérica bovina). El carril 2 corresponde a MI-BSA. El carril 3 al estándar de $1 \mathrm{~kb}$ con tamaños entre los 250 y los 10000 bp y el carril 4 a MI.

El LPS es una estructura propia de la ME de los microorganismos Gram(-) (Cué y Morejón, 1998; Pérez et al., 2004; Pérez et al., 2007), por lo tanto, es esperable que al separar ambas membranas, éste se encuentre principalmente en la ME. Producto del proceso de solubilización de membranas es posible encontrar LPS en la MI pero en una menor concentración. Esto se observa claramente en el Gráfico 1. 
Gráfico 1: Determinación de LPS en mg/ml con ensayo Purpald. Evaluación de muestras de MI y ME de cepa JM 109 de E.coli, asociadas a BSA (albúmina sérica bovina) y OVA (ovoalbúmina).

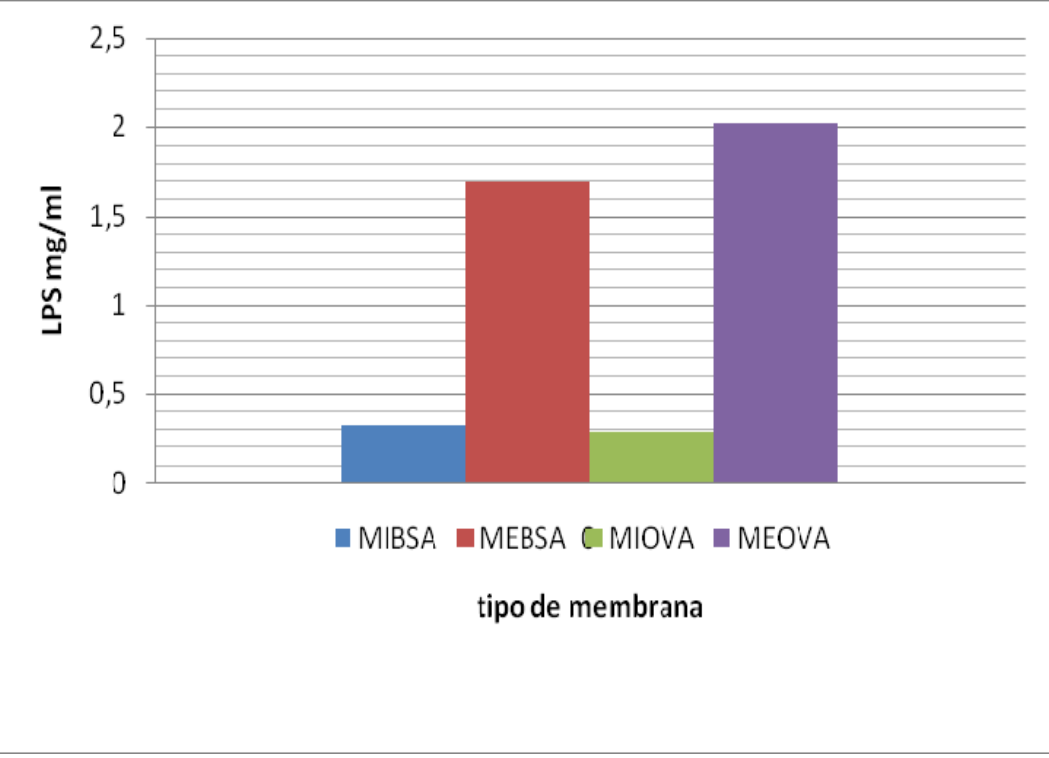

El LPS de bacterias Gram (-) es el MAMP más potente descrito, además es altamente tóxico cuando está libre. Sin embargo al ser incorporado en estructuras vesiculares reduce su toxicidad y reactogenicidad (Pérez et al., 2007).

La determinación de la proteína antigénica BSA incorporada en las vesículas de liposomas fue medida con la técnica Bradford. De una concentración inicial de incorporación de $500 \mu \mathrm{g} / \mathrm{ml}$ de proteína en muestras de MI y ME, se obtuvo los siguientes datos observados en la Tabla 1

Tabla 1: Concentración de proteína incorporada $(\mu \mathrm{g} / \mathrm{ml})$ y porcentaje de eficiencia promedio $(\%)$ de la proteína antigénica BSA en MI y ME de la cepa JM109 de E.coli.

\begin{tabular}{ccc}
\hline Tipo de & Incorporación & Eficiencia \\
membrana & BSA $(\mu \mathrm{g} / \mathrm{ml})$ & $(\%)$
\end{tabular}

\begin{tabular}{ccc}
\hline MI & 425,5 & 85,1 \\
ME & 365,5 & 73,1 \\
\hline
\end{tabular}

La Tabla 1 muestra que la concentración de proteína incorporada es altamente eficiente, principalmente en la MI, donde el porcentaje de eficiencia fue de $85,1 \%$.
En la Tabla 2 se observan los diferentes valores de tamaño y potencial zeta de los liposomas al incorporar BSA y OVA medidas en diferentes ensayos.

Las muestras que contienen BSA presentan valores de tamaño mayores tanto en MI $(434,6 \mathrm{~nm})$ como ME (350,8 nm) en relación a los obtenidos al medir muestras con OVA con valores de MI de 290,1 nm y de ME de 336,2 nm, considerando iguales condiciones de formulación, pero generadas en diferentes ensayos.

Se han descrito tamaños de liposomas incluso más pequeños de $83,2 \mathrm{~nm}$ y $163,5 \mathrm{~nm}$, pero sin proteína incorporada (Wang et al., 2010).

Al comparar los valores de tamaño y potencial zeta obtenidos para las partículas que contienen BSA y OVA medidas frescas (F) y después del secado por atomización (S) se observan leves aumentos de tamaño en las partículas posterior al secado. El potencial zeta presenta rangos de negatividad que fluctúan entre los $-17,4 \mathrm{mV}$ y los $-42,6 \mathrm{mV}$. Estos valores indicarían diferentes niveles de estabilidad de partículas en suspensión debido a la carga superficial que presentan los liposomas a un $\mathrm{pH}$ determinado. Se sabe que valores $>30 \mathrm{mV}$ indican micelas coloidales positivas muy estables y que valores $<-30 \mathrm{mV}$ corresponden a micelas negativas estables (Malvern Instrument, 2004). 
El reconocimiento por parte de las CPA pareciera ser más eficiente al incorporar partículas cargadas positivamente, pero también se describen respuestas con partículas de carga negativa (Carmona-Ribeiro, 2010).

Tabla 2: Tamaño de partícula (nm) y potencial zeta $(\mathrm{mV})$ en muestras de MI y ME provenientes de la cepa JM 109 de E.coli frescas (F) y secas (S). Se midió BSA (albúmina sérica bovina) y OVA (ovoalbúmina).

\begin{tabular}{cccc}
\hline \multicolumn{2}{c}{ Ensayo } & \multicolumn{2}{c}{ BSA } \\
\hline MI (F) & $\mathrm{ME}$ & $\mathrm{MI}(\mathrm{F})$ & $\mathrm{ME}$ \\
& $(\mathrm{F})$ & & $(\mathrm{F})$ \\
$\mathbf{4 3 4 , 6}$ & 350,8 & 290,1 & 336,2 \\
$\mathbf{n m}$ & $\mathrm{nm}$ & $\mathrm{nm}$ & $\mathrm{nm}$ \\
$\mathbf{- 3 0 , 3}$ & $-17,6$ & $-17,4$ & $-42,6$ \\
$\mathbf{m V}$ & $\mathrm{mV}$ & $\mathrm{mV}$ & $\mathrm{mV}$ \\
$\mathbf{( S )}$ & $\mathbf{( S )}$ & $(\mathrm{S})$ & $(\mathrm{S})$ \\
$\mathbf{4 1 9 , 6}$ & 452,1 & 301,7 & 510,8 \\
$\mathbf{n m}$ & $\mathrm{nm}$ & $\mathrm{nm}$ & $\mathrm{nm}$ \\
$\mathbf{- 1 8 , 3}$ & $-32,4$ & $-26,1$ & $-32,2$ \\
$\mathbf{m V}$ & $\mathrm{mV}$ & $\mathrm{mV}$ & $\mathrm{mV}$ \\
& & & \\
\hline
\end{tabular}

Las Fig.4 y 5, muestran partículas de alrededor de 100 y $200 \mathrm{~nm}$. Éstas se observan redondeadas, de contornos definidos $\mathrm{y}$ se pueden ver aisladas $\mathrm{y}$ agrupadas. En relación al tamaño de las partículas, las fotografiadas por el TEM no concuerdan con los datos obtenidos en el equipo Zeta Plus. Esto sería producto de que las partículas se encontraban aglomeradas al momento de la medición. Un tamaño inferior de los liposomas, entre 100 y $200 \mathrm{~nm}$, es posible ya que éstos presentan grandes variaciones de tamaño, pudiendo fluctuar entre los $50 \mathrm{~nm}$ y los 10 $\mu \mathrm{m}$ (Kaufmann, 2004). Pero se ha descrito que el óptimo reconocimiento por parte de las CPA, sería con partículas de diámetros aproximados de $500 \mathrm{~nm}$ (Carmona-Ribeiro, 2010).

La Fig.4 permite comparar liposomas formulados a partir de MI, con distintas proteínas (BSA y OVA) y sometidas a dos procedimientos que permiten comparar variaciones físicas de los liposomas (muestras congeladas y secas por atomización). Los liposomas, en las condiciones antes mencionadas, se observan de tamaños similares. El tamaño fue medido en relación al diámetro de la circunferencia del liposoma y no considera el halo difuso que se forma alrededor de éstos. Las muestras que contienen BSA se visualizan con contornos bien definidos, a diferencia de los liposomas que contienen OVA.

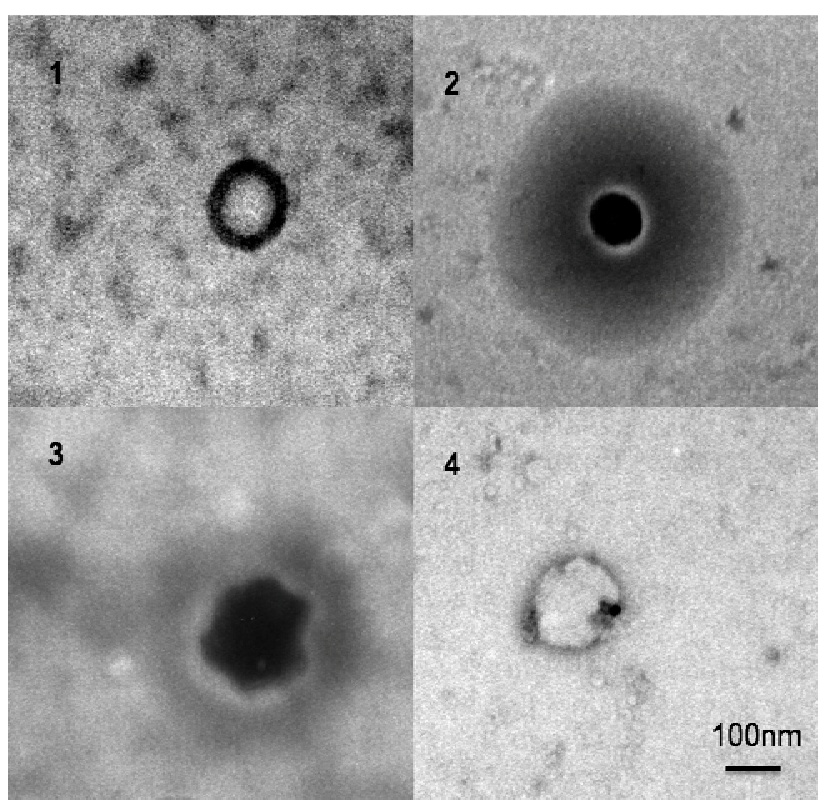

Fig. 4. Imágenes de liposomas en Microscopía Electrónica de Transmisión (TEM) a 50000X en muestras de MI de cepa JM 109 de E. coli sometidos a dos procedimientos (congelados y secos). (1) liposomas de MI con BSA congelados; (2) MI con BSA secos; (3) MI con OVA congelados y (4) MI con OVA secos.

La Fig. 5 permite comparar liposomas formulados a partir de ME con distintas proteínas (BSA y OVA) sometidos a dos procedimientos (congelados y secas por atomización). Los que contienen BSA se observan ovalados y de contornos definidos. En relación al tamaño, los secos se visualizan levemente más grandes que los congelados. Los que contienen OVA son más redondeados y de un diámetro levemente mayor. 


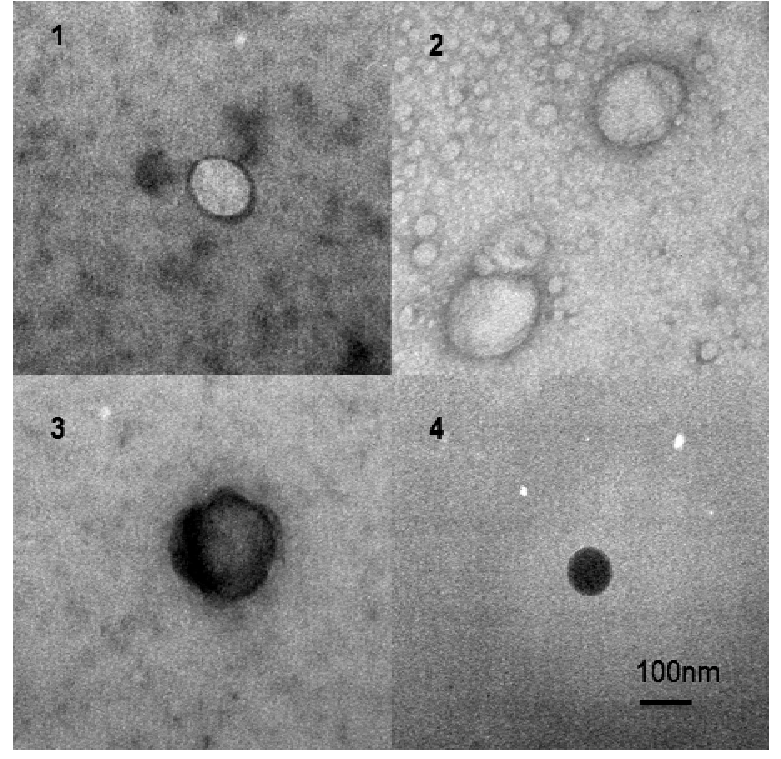

Fig. 5. Imágenes de liposomas en Microscopía Electrónica de Transmisión (TEM) a 50000X en muestras de ME de cepa JM 109 de E. coli sometidos a dos procedimientos (congelados y secos). (1) liposomas de ME con BSA congelados; (2) ME con BSA secos; (3) ME con OVA congelados y (4) patrón de medición.

El secado por atomización, permite pulverizar la muestra sometiéndola a altas temperaturas, entre 100 y $150{ }^{\circ} \mathrm{C}$, sin alterar las propiedades físicas de los liposomas ya que son rápidamente enfriados (Chougule et al., 2007). Esto es corroborado al visualizar las imágenes entregadas por el TEM (Fig. 4 y 5) donde se observan los liposomas sin daño aparente. El tamaño de las partículas secas es levemente superior a las no secas, según los datos entregados por el equipo Zeta Plus como por las imágenes del TEM.

\section{Conclusiones}

Se pueden formular liposomas de MI y ME de microorganismos apatógenos.

La ME de los microorganismos contiene mayor cantidad de LPS, porinas y DNA bacteriano.

El DNA bacteriano unido a ME se obtiene debido al proceso de solubilización realizado.

La MI contiene menor cantidad de LPS, porinas y DNA bacteriano, lo que permitiría generar adyuvantes menos reactogénicos, pero con la cantidad necesaria de MAMPs para estimular la respuesta inmune.

La eficiencia de incorporación de la proteína antigénica en ambas membranas es variable, siendo levemente mayor en la MI. Esto demuestra que es factible generar liposomas como adyuvantes con diferentes antígenos.

El proceso de secado por atomización al que fueron sometidos los liposomas no altera su estructura al ser observados en el TEM.

Los liposomas generados presentan cargas negativas debido a que provienen de membranas de microorganismos igualmente cargadas.

Las imágenes entregadas por el TEM muestran diferencias en relación a la medición realizada por el equipo Zeta Plus debido a la aglomeración de partículas que se produce posterior a la diálisis.

\section{Referencias}

1. BUCAREY, S. 2006. Tesis Doctoral. Caracterización funcional de los genes involucrados en el transporte de nucleosidos en Salmonella enterica serovar Typhi: Implicancias en patogenicidad. Pontificia Universidad Católica de Chile. Facultad de Ciencias Biológicas.

2. CARMONA-RIBEIRO, A. 2010. Biomimetic nanoparticles: preparation, characterization and biomedical applications. Inter. J. Nanomed. 5: 249-259.

3. CHOUGUle, M.; PADHI, B.; MISRA, A. 2007. Development of spray dried liposomal dry powder inhaler of dapsone. Pharm Schitech. 9 (1): 47-53.

4. CUÉ, M.; MOREJÓN, M. 1998. Antibacterianos de acción sistémica. Parte I. Antibióticos betalactámicos. Rev. Cubana Med. Gen. Integr. 14 (4): 347-361.

5. HEIT, A.; BUSCH, D.H.; WAGNER, H.; SCHMITZ, F. 2008. Vaccine protocols for enhanced immunogenicity of exogenous antigens. Inter. J. Med. Microb. 298: 27-32.

6. KAUFMANN S. 2004. Novel Vaccination Strategies. Ed. WILEY-VCH Verlag GmbH 
\& Co. KGaA. Germany. Part II: 19-31; Part III: $115-121$.

7. LEE, C.H.; TSAI, C.M. 1999. Quantification of bacterial lipopolysaccharides by de Purpald assay: Measuring formaldehyde generated from 2keto-3-deoxyoctonate and heptose at the inner core by periodate oxidation. Anal. Bioch. 267: 161-168.

8. MALVERN INSTRUMENT, INC. 2004. Potencial Zeta. Un curso completo en cinco minutos. Ed. Malvern Inst. Catálogo ZetaMeter.

(http://redalyc.uaemex.mx/redalyc/pdf/939/9 3912989004.pdf).

9. MESCHER, M.; CURTSINGER, J.M.; AGARWAL, P.; CASEY, K.; GERNER, M.; HAMMERBECK, C.; POPESCU, F.; XIAO, Z. 2006. Signals required for programming effector and memory development by $\mathrm{CD} 8+\mathrm{T}$-cells. Immunol. Rev. 211: 81-92.

10. PEETLA, C.; STINE, A.; LABHASETWAR, V. 2009. Biophysical Interactions with Model Lipid Membranes: Applications in Drug Discovery and Drug Delivery. Molec. Pharm. 6 (5): 1264-1276.

11. PÉREZ, O; BRACHO, G; LASTRE, M; MORA, N; DEL CAMPO, J; GIL, D; ZAYAS, C; ACEVEDO, R; GONZÁLEZ, D; LÓPEZ, JA; TABOADA, C; TURTLE, C; SOLIS, RL. 2004. Novel adjuvant based on a proteoliposome derived cochleate structure containing native lipopolysaccharide as a pathogen-associated molecular pattern. Immunol. Cell. Biol. 82 (6): 603-610.

12. PÉREZ, O.; LASTRE, M.; CABRERA, O.; DEL CAMPO, J.; BRACHO, G.; CUELLO, M.; BALBOA, J.; ACEVEDO, R.; ZAYAS, C.; GIL, D.; MORA, N.; GONZÁLEZ, D.; PÉREZ, R.; GONZÁLEZ, E.; BARBERÁ, R.; FAJARDO, E.M.; SIERRAS, G.; SOLIS, R.L.; CAMPAS, C. 2007. New vaccines require potent adjuvants like AFPL1 and AFCo1. Scan. J. Immunol. 66: 271-277.
13. PIOVESAN, G.; ANDRADE, M.H. 2004. Phospholipid dry powders produced by spray drying processing: Structural, thermodynamic and physical properties. Powder Tech. 145: 139-148.

14. REDDY, S.T.; SWARTZ, M.A.; HUBBELL, J.A. 2006. Targeting dendritic cells with biomaterials: Developing the next generation of vaccines. TRENDS in Immunol. 27 (12): 573-579.

15. RICHARDS, R.; ALVING, C.; WASSEF, N. 1996. Liposomal subunit vaccines: Effects of lipid A and aluminum hydroxide on immunogenicity. J. Pharm. Sciences 85 (12): 1286-1289.

16. ROBINSON, A.; HUDSON, M.J.; CRANAGE M.P. 2003. Methods in molecular medicine: Vaccine protocolos. 2nd ed. 87: 175-180.

17. SÁENZ, L.; NEIRA-CARRILLO, A.; PAREDES, R.; CORTÉS M.; BUCAREY, S.; ARIAS, J.L. 2009. Chitosan formulations improve the inmunogenicity of a GnRH-I peptide-based vaccine. Inter. J. Pharm. 369: 64-71.

18. SUTCLIFFE, I.; HARRINGTON, D. 2004. Lipoproteins of mycobacterium tuberculosis: an abundant and functionally diverse class of cell envelope components. FEMS Microbiol Rev. 28:645-759. (http://onlinelibrary.wiley.com/doi/10.1016/j .femsre.2004.06.002/pdf).

19. ULRICH, A. 2002. Biophysical aspects of using liposomes as delivery vehicles. Bioscience Reports 22 (2): 129-150.

20. WAGNER, H.; BAUER, S. 2006. All is not Toll: new pathways in DNA recognition. J. Exp. Med. 203: 265-268.

21. WANG, H.; ZHANG, S.; LIAO, Z.; WANG, CH.; LIU, Y.; FENG, S.; JIANG, X.; CHANG, J. 2010. PEGlated magnetic polymeric liposome anchored with TAT for delivery of drugs across the blood-spinal cord barrier. Biomaterials 31: 6589-6596. 